\title{
High Spatial Resolution Digital Positron Emission Tomography Images With Dedicated Source-to- background Algorithm for Radiotherapy Planning
}

\author{
TAKAHIRO WATAKABE ${ }^{1}$, RYO TOYA $^{1}$, TETSUO SAITO $^{1}$, TOMOHIKO MATSUYAMA $^{1}$, \\ SHINYA SHIRAISHI ${ }^{2}$, YUDAI KAI ${ }^{3,4}$, YOSHINOBU SHIMOHIGASHI ${ }^{3}$ and NATSUO OYA ${ }^{1}$ \\ ${ }^{1}$ Department of Radiation Oncology, Faculty of Life Sciences, Kumamoto University, Kumamoto, Japan; \\ ${ }^{2}$ Department of Diagnostic Radiology, Faculty of Life Sciences, Kumamoto University, Kumamoto, Japan; \\ ${ }^{3}$ Department of Radiological Technology, Kumamoto University Hospital, Kumamoto, Japan; \\ ${ }^{4}$ Department of Health Sciences, Graduate School of Medical Sciences, Kyushu University, Fukuoka, Japan
}

\begin{abstract}
Background/Aim: To evaluate the utility of high spatial resolution digital positron emission tomography images with the source-to-background ratio (SBR) algorithm for gross tumour volume (GTV) delineation. Materials and Methods: The bowl and spheres $(10-37 \mathrm{~mm})$ were filled with fluoro-2-deoxyD-glucose to achieve 4-16 times background radioactivity. The images were reconstructed using three isotropic voxel sizes. The $S B R$ and percentage threshold (TH) to $S U V_{\max }$ were calculated. The plots between $S B R$ and $T H$ were fitted using a regression equation. The contoured volumes (CVs) of the spheres were calculated by applying TH. Results: TH was 38.6+75.0/SBR for $4 \mathrm{~mm}$ voxel size; $39.6+37.0 / \mathrm{SBR}$ for $2 \mathrm{~mm}$; and $38.8+35.2 / \mathrm{SBR}$ for $1 \mathrm{~mm}$. The mean relative errors between $C V$ and true volume for 4, 2, and $1 \mathrm{~mm}$ voxel sizes were $15 \%, 7 \%$, and $7 \%$, respectively. Conclusion: The present technique is useful for GTV delineation with reduced contouring error.
\end{abstract}

Functional imaging using $\left[{ }^{18} \mathrm{~F}\right]$-fluoro-2-deoxy-D-glucose (FDG)-positron emission tomography (PET), which provides

This article is freely accessible online.

Presentation at a conference: The $61^{\text {st }}$ Annual Meeting of the American Society for Radiation Oncology, September 15-18, 2019, Chicago, IL, USA.

Correspondence to: Ryo Toya, Department of Radiation Oncology, Faculty of Life Sciences, Kumamoto University, 1-1-1 Honjo, Chuo-ku, Kumamoto 860-8556, Japan. Tel: +81 963735522, Fax: +81963735522, e-mail: ryo108@kumamoto-u.ac.jp ORCID ID: 0000-0001-9764-5718

Key Words: Positron emission tomography, radiotherapy planning, gross tumour volume, auto-delineation, digital positron emission tomography. information pertaining to glucose metabolism, has been widely used for radiotherapy (RT) planning (1-3). Autodelineation of gross tumour volume (GTV) using threshold based on the standardised uptake value (SUV) is a useful method for RT planning (4-6). The optimal percentage threshold $(\mathrm{TH})$ to the maximum SUV $\left(\mathrm{SUV}_{\max }\right)$ of the tumour reportedly ranges from $40 \%$ to $50 \%(4,6,7)$. However, some studies have shown that tumour size and background affect the TH; i.e., smaller lesions and a higher background activity necessitate a higher $\mathrm{TH}(8,9)$. The source-to-background ratio (SBR) algorithm, which is based on the inverse function $(y=a+b \times 1 / x)$ between the SBR and $\mathrm{TH}$, is widely accepted as a sophisticated and practical approach to address the effect of tumour size and background on TH $(10,11)$. Previous studies have demonstrated the clinical value of the SBR algorithm for RT planning $(10,11)$. Van Baardwijk et al. have compared the SBR-based autodelineation with pathological findings in 23 patients with non-small-cell lung cancer (11). They found a strong correlation between the maximal tumour diameter of the SBR-based auto-delineation and the macroscopic diameter of primary tumours (Pearson correlation coefficient: 0.90). They have also evaluated the interobserver variability by calculating the concordance index (CI) for tumour delineation among the five observers. They found that the integration of SBR-based auto-delineation into manual delineation based on computed tomography (CT) images significantly increased the CI from 0.70 to 0.74 for primary tumours $(p<0.001)$. Daisne et al. have estimated the volume of SBR-based autodelineation and manual delineation based on the CT and magnetic resonance (MR) images and compared the volumes with surgical specimen obtained from nine patients with laryngeal cancer (10). The average mismatch of the volume between the imaging modalities and the surgical specimen was $46 \%$ for the SBR-based auto-delineation, $81 \%$ for 


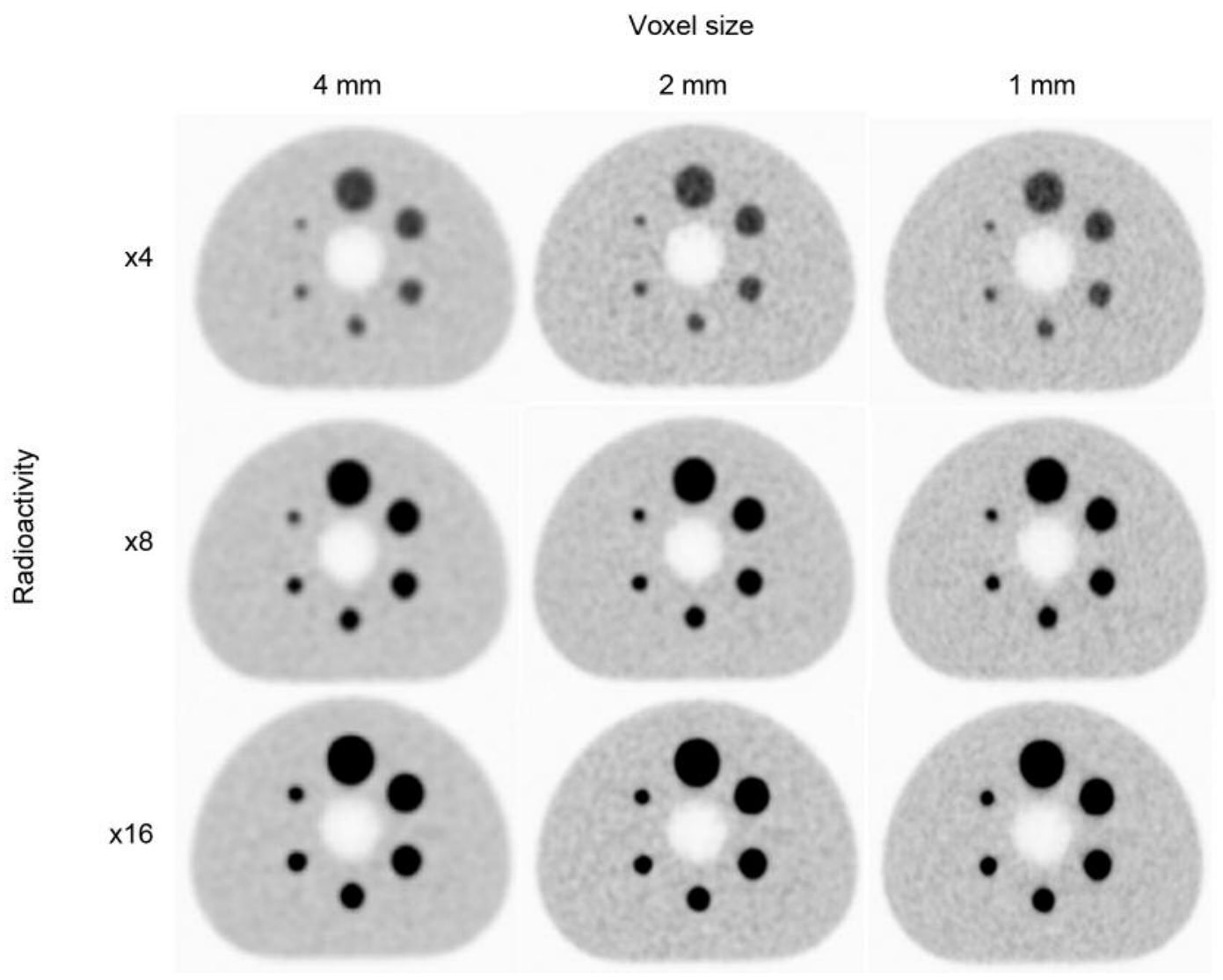

Figure 1. Positron emission tomography images with three radioactivity levels and three voxel sizes.

manual delineation based on the CT images, and $107 \%$ for manual delineation based on the MR images. They concluded that SBR-based auto-delineation is the most accurate method for delineation of GTV among these three methods.

Conventional PET images have a limited spatial resolution (typical voxel size: $4-5 \mathrm{~mm}$ ), and are influenced by lesion size and background on the TH (8). State-of-the-art digital PET provides higher spatial resolution images with a minimal voxel size of $1 \mathrm{~mm}$ (12-14). To the best of our knowledge, the introduction of the high spatial resolution digital PET images in radiotherapy planning has not been discussed. We conducted a phantom study to evaluate the utility of high spatial resolution digital PET images with SBR algorithm for auto-delineation of GTV in radiotherapy planning.

\section{Materials and Methods}

Phantoms and FDG-PET/CT imaging. We used the National Electrical Manufacturers Association International Electrotechnical Commission body phantom set (Data Spectrum Corporation, Hillsborough, NC, USA), which consists of an elliptical bowl (volume: $10.3 \mathrm{l}$ ) and six spheres (diameter range $=10-37 \mathrm{~mm}$ ). The bowl was filled with $2.65 \mathrm{kBq} / \mathrm{ml}$ FDG (Nihon Medi-Physics, Tokyo,
Japan), and the spheres were filled with FDG to achieve 4, 8, and 16 times the background radioactivity to obtain the various SBRs (15). PET imaging was conducted using a whole-body 3D digital PET/CT scanner (Vereos; Philips Medical Systems, Cleveland, OH, USA). We acquired CT images [414 mA, $120 \mathrm{kV}, 512 \times 512$ matrix, $600 \mathrm{~mm}$ field of view (FOV), $0.8 \mathrm{~mm}$ slice thickness] and then performed a PET scan using one bed position (FOV $576 \mathrm{~mm}$; scan duration: $5 \mathrm{~min}$ ). Attenuation correction was conducted with CT transmission data, and emission images were reconstructed using list-mode ordered subset expectation maximisation time-of-flight PET imaging, with three isotropic voxel sizes of 4,2 , and $1 \mathrm{~mm}$ and without point spread function. For each voxel size, we used a fixed number of iterations and subsets based on the previous report and our preliminary experiment (three iterations and 13 subsets for 4 and $2 \mathrm{~mm}$; three iterations and six subsets for $1 \mathrm{~mm}$ ) (13). Post-reconstruction smoothing filter was not applied.

Image analysis. PET image files were transferred to the Velocity oncology imaging informatics system version 3.0.2 (Varian Medical Systems, Inc, Palo Alto, CA, USA) (Figure 1). We recorded the $\mathrm{SUV}_{\text {max }}$ of the spheres and background activity, which is calculated from the average activity in volume of interest of approximately 100 $\mathrm{ml}$ delineated in the phantom outside the sphere (16). The $\mathrm{SUV}_{\max }$, SBR, and TH were estimated for each sphere in the different reconstructed images with the three voxel sizes. The plots between 
the SBR and $\mathrm{TH}$ were fitted using a regression equation $(y=a+b \times 1 / x)$. To verify the validity of the relationships between SBR and TH established above, the contoured volume (CV) was calculated by applying the TH determined using regression equations. To compare CV with the true volume of sphere (TV), we estimated the mean relative error for each voxel size. Relative error was calculated using the following equation:

Relative error $(\%)=(\mathrm{CV}-\mathrm{TV}) / \mathrm{TV} \times 100$

Statistical analysis. All statistical analyses were performed using SPSS version 25.0 (IBM, Armonk, NY, USA). Friedman test was performed to compare the $\mathrm{SUV}_{\max }$ for six sphere sizes and reconstructed images with the three voxel sizes. Dunn-Bonferroni test was performed to compare between images with different voxel sizes as a post hoc analysis if the Friedman test result was significant (8). Regression analyses were performed to evaluate the relationship between the SBR and TH. $p$-Values $<0.05$ were considered significant.

\section{Results}

Eighteen groups of the $\mathrm{SUV}_{\max }, \mathrm{SBR}$ and TH were acquired from the images of each voxel size. Differences in the $\mathrm{SUV}_{\max }$ were significant between six sphere sizes in the images with 4 $\mathrm{mm}$ voxel size $(p=0.010), 2 \mathrm{~mm}(p=0.018)$, and $1 \mathrm{~mm}$ $(p=0.012)$ (Table I, Figure 2). Differences in the $\mathrm{SUV}_{\max }$ were significant between the three voxel sizes $(p<0.001)$. The $\mathrm{SUV}_{\text {max }}$ of the images with $4 \mathrm{~mm}$ voxel size were significantly lower than the $\mathrm{SUV}_{\max }$ of the images with $2 \mathrm{~mm}(p=0.003)$ and $1 \mathrm{~mm}(p<0.001)$. There was no significant difference in the $\mathrm{SUV}_{\max }$ between the images with $2 \mathrm{~mm}$ and $1 \mathrm{~mm}$ voxel size $(p=0.29)$. The relationship between the SBR and TH was described as follows: $\mathrm{TH}=38.6+75.0 / \mathrm{SBR}$ for $4 \mathrm{~mm}$ voxel size $\left(\mathrm{R}^{2}=0.69, p<0.001\right) ; \mathrm{TH}=39.6+37.0 / \mathrm{SBR}$ for $2 \mathrm{~mm}$ voxel size $\left(\mathrm{R}^{2}=0.58, p<0.001\right)$; and $\mathrm{TH}=38.8+35.2 / \mathrm{SBR}$ for $1 \mathrm{~mm}$ voxel size $\left(\mathrm{R}^{2}=0.60, p<0.001\right)$ (Figure 3$)$. The mean relative error for 4,2 , and $1 \mathrm{~mm}$ voxel size was $15 \%, 7 \%$, and $7 \%$, respectively (Figure 4). Figure 5 shows the waterfall plots of relative error of CVs based on the above formulae for three voxel sizes.

\section{Discussion}

One of the limitations of conventional PET, which has a photomultiplier tube, is the relatively low spatial resolution; this results in a partial volume effect that affects the images both visually and quantitatively and encompasses a low signalto-noise ratio $(8,9)$. Digital PET, which has a solid-state digital photon counting PET detector, helps overcome this limitation $(12-14,17,18)$. However, our results suggested that the partial volume effect was unavoidable even in the high spatial resolution images with $2 \mathrm{~mm}$ and $1 \mathrm{~mm}$ voxel sizes. Our results also suggested that the degree of the partial volume effect depended on the spatial resolution of the images. Particularly, the partial volume effect was significantly greater with $4 \mathrm{~mm}$ voxel size than with $2 \mathrm{~mm}$ or smaller.
Table I. The $S U V_{\max }$ of six spheres for three source-to-background ratios and three voxel sizes.

\begin{tabular}{lrrrr}
\hline Source radioactivity & Diameter & \multicolumn{3}{c}{$\mathrm{SUV}_{\text {max }}$ by voxel sizes } \\
\cline { 3 - 5 } & & $4 \mathrm{~mm}$ & $2 \mathrm{~mm}$ & $1 \mathrm{~mm}$ \\
\hline$\times 4$ & $10 \mathrm{~mm}$ & 2.28 & 3.44 & 3.36 \\
& $13 \mathrm{~mm}$ & 3.27 & 4.10 & 4.00 \\
& $17 \mathrm{~mm}$ & 3.59 & 3.95 & 4.21 \\
& $22 \mathrm{~mm}$ & 4.06 & 4.45 & 4.91 \\
& $28 \mathrm{~mm}$ & 4.20 & 4.70 & 4.83 \\
& $37 \mathrm{~mm}$ & 4.30 & 4.63 & 4.84 \\
$\times 8$ & $10 \mathrm{~mm}$ & 3.69 & 6.60 & 6.50 \\
& $13 \mathrm{~mm}$ & 5.99 & 7.81 & 7.82 \\
& $17 \mathrm{~mm}$ & 7.40 & 8.06 & 8.54 \\
& $22 \mathrm{~mm}$ & 8.05 & 8.47 & 9.07 \\
& $28 \mathrm{~mm}$ & 8.16 & 8.22 & 8.78 \\
& $37 \mathrm{~mm}$ & 8.28 & 8.55 & 9.07 \\
$\times 16$ & $10 \mathrm{~mm}$ & 8.22 & 12.84 & 14.50 \\
& $13 \mathrm{~mm}$ & 13.51 & 16.81 & 16.40 \\
& $17 \mathrm{~mm}$ & 15.20 & 16.08 & 16.40 \\
& $22 \mathrm{~mm}$ & 15.33 & 16.84 & 17.40 \\
& $28 \mathrm{~mm}$ & 16.35 & 17.00 & 17.12 \\
& $37 \mathrm{~mm}$ & 16.66 & 17.31 & 17.69 \\
\hline
\end{tabular}

SUV: Standardised uptake value.

Our results demonstrated that the SBR algorithm is useful not only for conventional resolution images with voxel size of $4 \mathrm{~mm}$ but also for high spatial resolution images with voxel size of 2 and $1 \mathrm{~mm}$. However, the SBR algorithm is strongly affected by the spatial resolution of PET images: the relationship between the SBR and TH for $4 \mathrm{~mm}$ voxel size differed greatly from that for 2 and $1 \mathrm{~mm}$. This difference in the SBR algorithm may be due to the difference in the partial volume effect between the images of the voxel sizes. Thus, the use of SBR algorithm based on the conventional PET images for auto-delineation of GTV based on high spatial resolution images may result in inappropriate GTV delineation, and the SBR algorithm for auto-delineation of GTV should be optimised on the basis of the spatial resolution of the PET images. Our results also suggested that the use of high spatial resolution images with isotropic voxel sizes of 2 or $1 \mathrm{~mm}$ reduces the contouring error compared with conventional resolution images with voxel size of $4 \mathrm{~mm}$. Introduction of the combination of high spatial resolution PET images and dedicated SBR algorithm for auto-delineation facilitate precise definition of GTV.

There are some limitations of our study. First, this was an experimental phantom study and could not replicate the clinical setting with respect to complex tumour shape and heterogeneous background activity. Second, we did not evaluate the influence of reconstruction algorithm on the SBR algorithm. This factor may slightly influence 


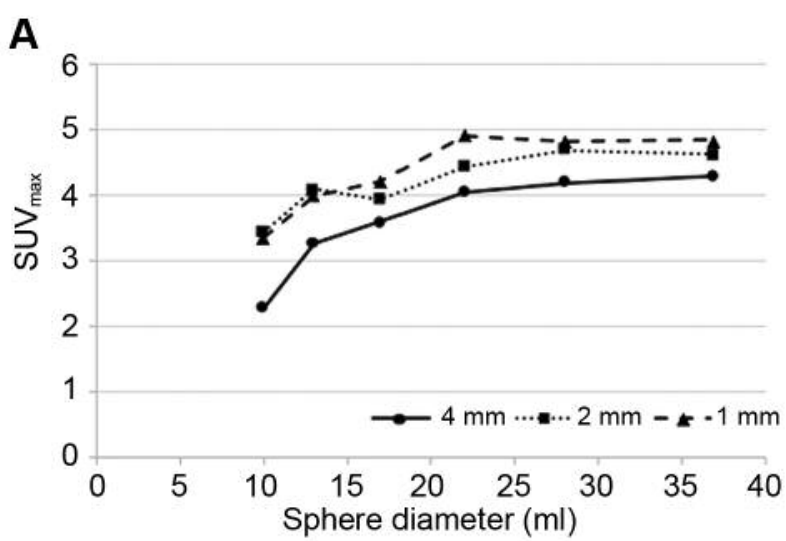

B

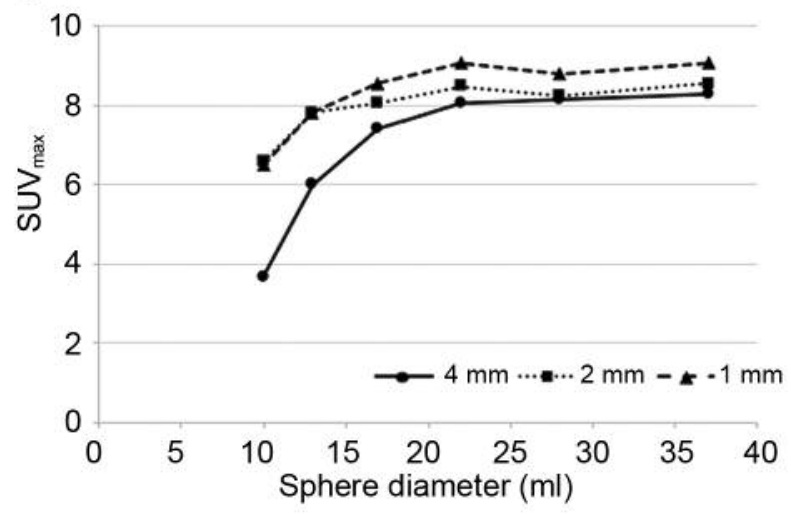

C

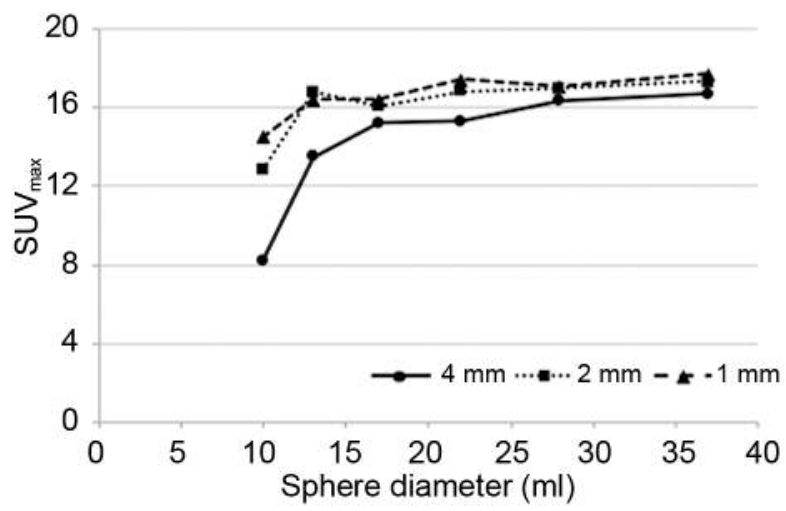

Figure 2. The $S U V_{\max }$ of the six spheres and three voxel sizes for radioactivities of $4(A), 8(B)$, and $16(C)$ times the background activity.

$\mathrm{SUV}_{\max }$ and the relationship between the SBR and TH (16). Further investigations are underway to address these issues.

In conclusion, high spatial resolution digital PET images with SBR algorithm are useful for auto-delineation of GTV and for reducing contouring error compared with using conventional resolution PET images. A dedicated SBR algorithm for the high-resolution digital PET images is required for precise tumour delineation.
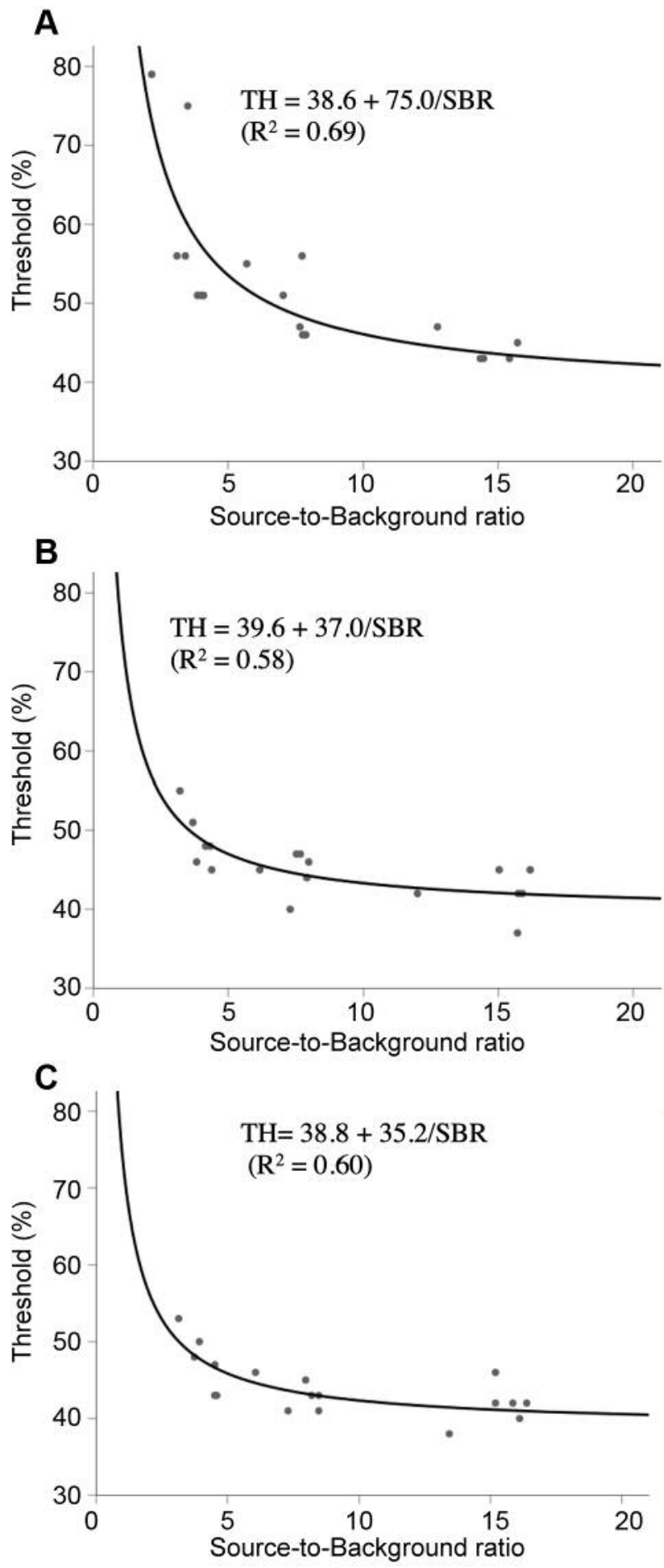

Figure 3. Relationship between the source-to-background ratio and the threshold with voxel sizes of $4 \mathrm{~mm}(A), 2 \mathrm{~mm}(B)$, and $1 \mathrm{~mm}(C)$.

\section{Conflicts of Interest}

The Authors declare that they have no conflicts of interest regarding this study. 

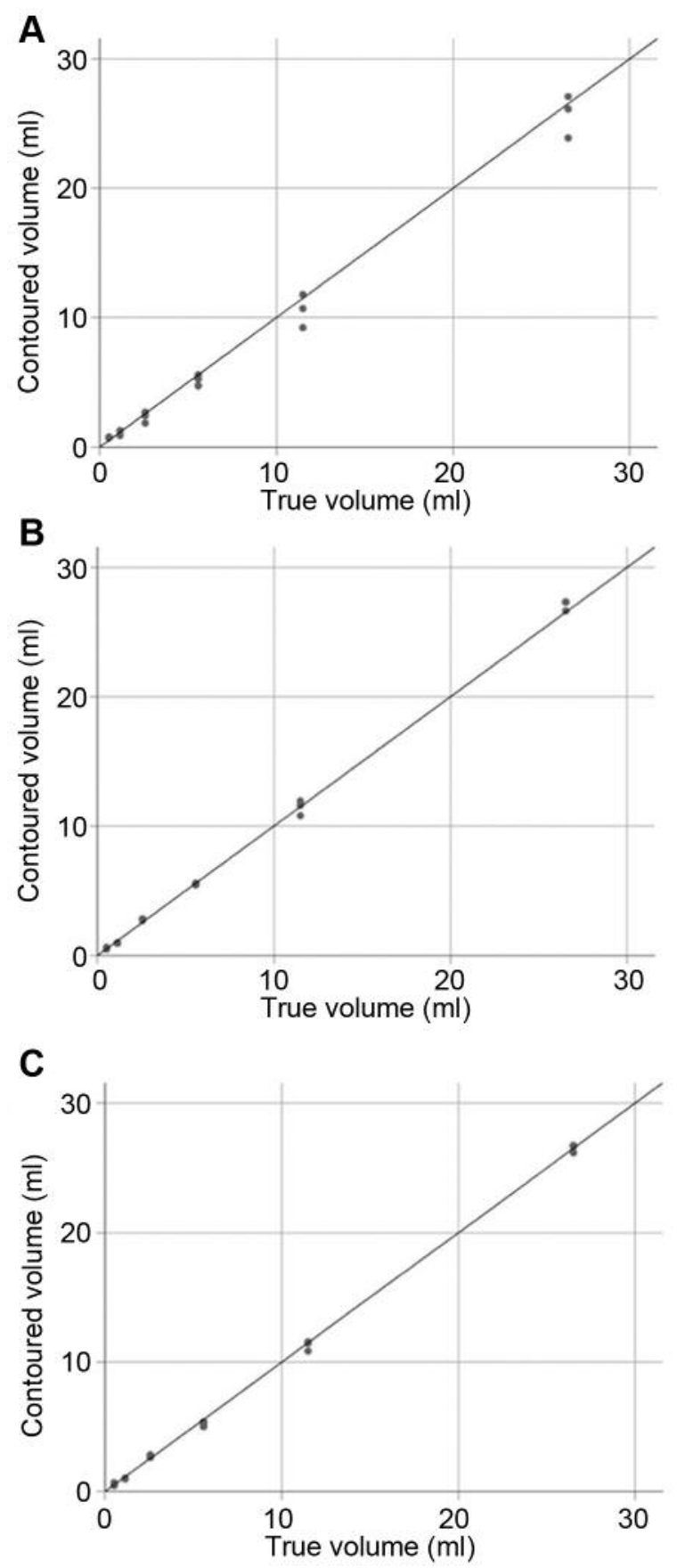

Figure 4. Relationship between the true volume and the contoured volume of the spheres based on the source-to-background algorithm with voxel sizes of $4 \mathrm{~mm}(A), 2 \mathrm{~mm}(B)$, and $1 \mathrm{~mm}(C)$.

\section{Authors' Contributions}

TW developed the study design; collected, analyzed, and interpreted the data; performed statistical analysis; and wrote the manuscript. RT developed the study design, analyzed and interpreted the data, and wrote the manuscript. TS, TM, and SS developed the study
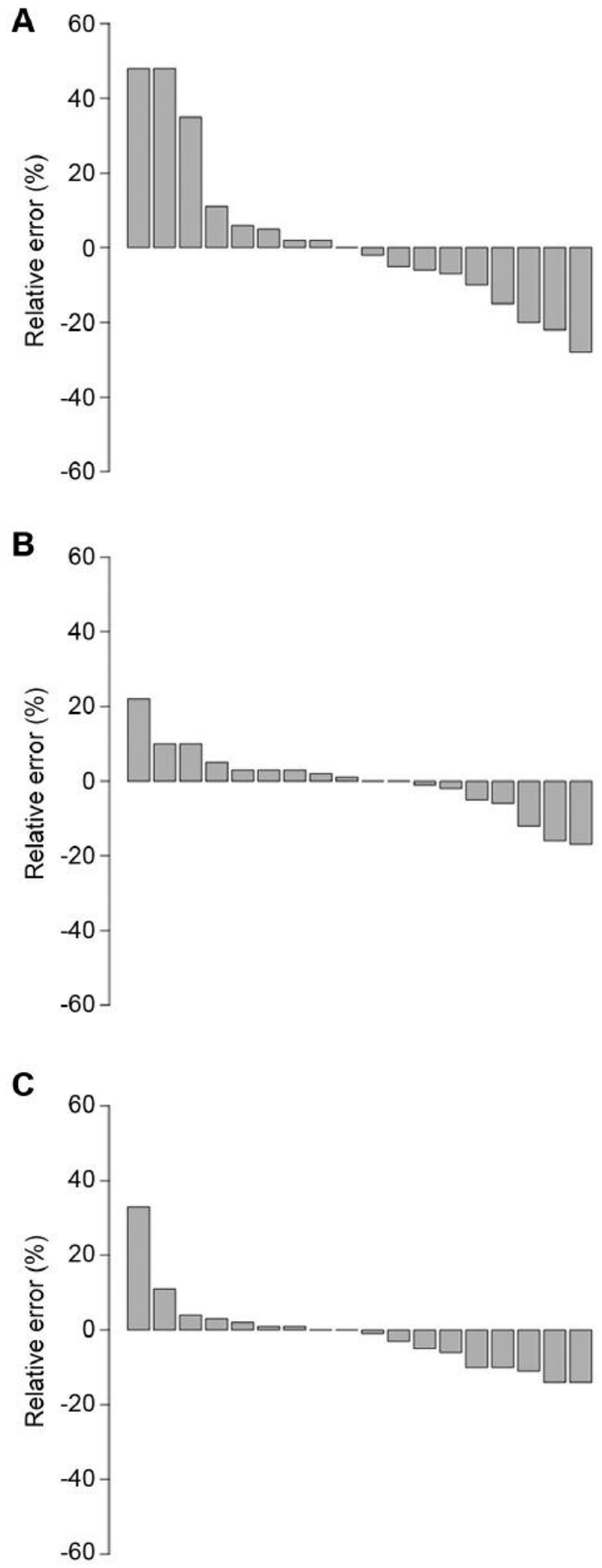

Figure 5. Relative error of contoured volume of the spheres based on the source-to-background algorithm with voxel sizes of $4 \mathrm{~mm}(A), 2 \mathrm{~mm}$ $(B)$, and $1 \mathrm{~mm}(C)$. 
design and analyzed and interpreted the data. YK and YS collected the data. NO developed the study design and interpreted the data. All Authors have read and approved the final manuscript.

\section{Acknowledgements}

This work was partially supported by the JSPS KAKENHI [grant number 18K07758].

\section{References}

1 Toya R, Matsuyama T, Saito T, Imuta M, Shiraishi S, Fukugawa Y, Iyama A, Watakabe T, Sakamoto F, Tsuda N, Shimohigashi Y, Kai Y, Murakami R, Yamashita Y and Oya N: Impact of hybrid FDG-PET/CT on gross tumor volume definition of cervical esophageal cancer: Reducing interobserver variation. J Radiat Res 60(3): 348-352, 2019. PMID: 30864652. DOI: 10.1093/jrr/rrz004

2 Murakami R, Uozumi H, Hirai T, Nishimura R, Katsuragawa S, Shiraishi S, Toya R, Tashiro K, Kawanaka K, Oya N, Tomiguchi S and Yamashita Y: Impact of FDG-PET/ CT fused imaging on tumor volume assessment of head-and-neck squamous cell carcinoma: Intermethod and interobserver variations. Acta Radiol 49(6): 693699, 2008. PMID: 18568563. DOI: 10.1080/02841850802027034

3 Toya R, Saito T, Matsuyama T, Kai Y, Shiraishi S, Murakami D, Yoshida R, Watakabe T, Sakamoto F, Tsuda N, Arimura H, Orita Y, Nakayama H and Oya N: Diagnostic value of FDG-PET/ CT for the identification of extranodal extension in patients with head and neck squamous cell carcinoma. Anticancer Res 40(4): 2073-2077, 2020. DOI: 10.21873/anticanres.14165

4 Wu K, Ung YC, Hornby J, Freeman M, Hwang D, Tsao MS, Dahele M, Darling G, Maziak DE, Tirona R, Mah K and Wong CS: PET CT thresholds for radiotherapy target definition in nonsmall-cell lung cancer: How close are we to the pathologic findings? Int J Radiat Oncol Biol Phys 77(3): 699-706, 2010. PMID: 19836163. DOI: 10.1016/j.ijrobp.2009.05.028

5 Yu J, Li X, Xing L, Mu D, Fu Z, Sun X, Sun X, Yang G, Zhang $B$, Sun $X$ and Ling CC: Comparison of tumor volumes as determined by pathologic examination and FDG-PET/CT images of non-small-cell lung cancer: A pilot study. Int J Radiat Oncol Biol Phys 75(5): 1468-1474, 2009. PMID: 19464822. DOI: 10.1016/j.ijrobp.2009.01.019

6 Burri RJ, Rangaswamy B, Kostakoglu L, Hoch B, Genden EM, Som PM and Kao J: Correlation of positron emission tomography standard uptake value and pathologic specimen size in cancer of the head and neck. Int J Radiat Oncol Biol Phys 71(3): 682-688, 2008. PMID: 18258379. DOI: 10.1016/j.jirobp.2007.10.055

7 Erdi YE, Rosenzweig K, Erdi AK, Macapinlac HA, Hu YC, Braban LE, Humm JL, Squire OD, Chui CS, Larson SM and Yorke ED: Radiotherapy treatment planning for patients with non-small cell lung cancer using positron emission tomography (PET). Radiother Oncol 62(1): 51-60, 2002. PMID: 11830312. DOI: $10.1016 / \mathrm{s} 0167-8140(01) 00470-4$

8 Toya R, Murakami R, Tashiro K, Yoshida M, Sakamoto F, Kawanaka K, Shiraishi S, Nakaguchi Y, Tsujita N, Oya N, Tomiguchi S and Yamashita Y: FDG-PET/ CT-based gross tumor volume contouring for radiation therapy planning: An experimental phantom study. J Radiat Res 53(2): 338-341, 2012. PMID: 22398846. DOI: 10.1269/jrr.10183

9 Murakami R, Uozumi H, Hirai T, Nishimura R, Shiraishi S, Ota K, Murakami D, Tomiguchi S, Oya N, Katsuragawa S and Yamashita Y: Impact of FDG-PET/CT imaging on nodal staging for head-and-neck squamous cell carcinoma. Int J Radiat Oncol Biol Phys 68(2): 377-382, 2007. PMID: 17321066. DOI: 10.1016/j.ijrobp.2006.12.032

10 Daisne JF, Duprez T, Weynand B, Lonneux M, Hamoir M, Reychler $\mathrm{H}$ and Gregoire V: Tumor volume in pharyngo-laryngeal squamous cell carcinoma: Comparison at CT, MR imaging, and FDG PET and validation with surgical specimen. Radiology 233(1): 93-100, 2004. PMID: 15317953. DOI: 10.1148/radiol.2331030660

11 van Baardwijk A, Bosmans G, Boersma L, Buijsen J, Wanders S, Hochstenbag M, van Suylen RJ, Dekker A, Dehing-Oberije C, Houben R, Bentzen SM, van Kroonenburgh M, Lambin P and De Ruysscher D: PET-CT-based auto-contouring in non-small-cell lung cancer correlates with pathology and reduces interobserver variability in the delineation of the primary tumor and involved nodal volumes. Int J Radiat Oncol Biol Phys 68(3): 771-778, 2007. PMID: 17398018. DOI: 10.1016/j.ijrobp.2006.12.067

12 Wright CL, Binzel K, Zhang J and Knopp MV: Advanced functional tumor imaging and precision nuclear medicine enabled by digital PET technologies. Contrast Media Mol Imaging 2017: 5260305, 2017. PMID: 29097926. DOI: 10.1155/2017/5260305

13 Koopman D, Groot Koerkamp M, Jager PL, Arkies H, Knollema S, Slump CH, Sanches PG and van Dalen JA: Digital PET compliance to earl accreditation specifications. EJNMMI Phys 4(1): 9, 2017. PMID: 28144857. DOI: 10.1186/s40658-017-0176-5

14 Koopman D, van Dalen JA, Lagerweij MC, Arkies H, de Boer J, Oostdijk AH, Slump CH and Jager PL: Improving the detection of small lesions using a state-of-the-art time-of-flight PET/CT system and small-voxel reconstructions. J Nucl Med Technol 43(1): 21-27, 2015. PMID: 25613334. DOI: 10.2967/jnmt.114.147215

15 Kawakami W, Takemura A, Yokoyama K, Nakajima K, Yokoyama $\mathrm{S}$ and Koshida K: The use of positron emission tomography/computed tomography imaging in radiation therapy: A phantom study for setting internal target volume of biological target volume. Radiat Oncol 10: 1, 2015. PMID: 25567003. DOI: $10.1186 / \mathrm{s} 13014-014-0315-2$

16 Daisne JF, Sibomana M, Bol A, Doumont T, Lonneux M and Gregoire V: Tri-dimensional automatic segmentation of PET volumes based on measured source-to-background ratios: Influence of reconstruction algorithms. Radiother Oncol 69(3): 247-250, 2003. PMID: 14644483. DOI: 10.1016/s0167-8140(03)00270-6

17 van der Vos CS, Koopman D, Rijnsdorp S, Arends AJ, Boellaard R, van Dalen JA, Lubberink M, Willemsen ATM and Visser EP: Quantification, improvement, and harmonization of small lesion detection with state-of-the-art PET. Eur J Nucl Med Mol Imaging 44(Suppl 1): 4-16, 2017. PMID: 28687866. DOI: 10.1007/s00259$017-3727-\mathrm{z}$

18 Nguyen NC, Vercher-Conejero $\mathrm{J}$ and Faulhaber P: Tumor volume delineation: A pilot study comparing a digital positronemission tomography prototype with an analog positronemission tomography system. World J Nucl Med 18(1): 45-51, 2019. PMID: 30774546. DOI: 10.4103/wjnm.WJNM_22_18

Received March 11, 2020

Revised March 28, 2020

Accepted March 29, 2020 